\title{
Microalgal cell disruption: Effect on the bioactivity and rheology of wheat bread
}

\author{
M. Cristiana Nunes ${ }^{a, *}$, Carla Graça ${ }^{a}$, Sanja Vlaisavljević ${ }^{\mathrm{b}}$, Ana Tenreiro ${ }^{\mathrm{c}}$, Isabel Sousa ${ }^{\mathrm{a}}$, \\ Anabela Raymundo ${ }^{a}$ \\ ${ }^{a}$ LEAF-Linking Landscape, Environment, Agriculture and Food, Instituto Superior de Agronomia, Universidade de Lisboa, Tapada da Ajuda, 1349-017 Lisboa, Portugal \\ ${ }^{\mathrm{b}}$ Department of Chemistry, Biochemistry and Environmental Protection, Faculty of Sciences, Trg Dositeja Obradovica 3, Novi Sad 21000, Serbia \\ ${ }^{\mathrm{c}}$ BioISI-Instituto de Biosistemas \& Ciências Integrativas, Faculdade de Ciências, Universidade de Lisboa, 1749-016 Lisboa, Portugal
}

\section{A R T I C L E I N F O}

\section{Keywords:}

Microalgal pretreatment

Chlorella vulgaris

Oscillatory tests

Texture

Antioxidant capacity

\begin{abstract}
A B S T R A C T
The aim of this study is to investigate the potential of the addition of a microalgal biomass to improve nutritional quality of bread. Microalgae contain a substantial amount of nutrients that are naturally encapsulated within cells, namely proteins, polysaccharides, polyunsaturated fatty acids and pigments (chlorophylls and carotenoids), which are capable of resisting harsh conditions during food processing. However, the cell wall integrity may significantly limit nutrient availability, and microalgal cell disruption is potentially required as a pretreatment.

A suspension of a fresh Chlorella vulgaris biomass $(0.88 \mathrm{~g} / \mathrm{L})$ was disrupted in a high-pressure homogenizer at $340 \mathrm{MPa}$ using 1 and 4 passages. The impact of the cell disruption method was evaluated in terms of the reduction in the number of intact cells and average colony diameter of the remaining cells using flow cytometry and microscopy.

Since cell disruption promotes the release of intracellular products, it can impart structural modifications to doughs and breads. Therefore, doughs and breads were prepared with the fresh C. vulgaris biomass (1.0 g of Cv/ $100 \mathrm{~g}$ of flour $+\mathrm{Cv}$ ), the disrupted biomass, or a commercial powder. Doughs were characterized in terms of texture and oscillatory rheology. The texture and colour of breads were also evaluated. Cell wall disruption affected the colour and texture of the breads, resulting in breads with a higher firmness. Furthermore, bioactivity was evaluated, and the reducing power of the bread extracts obtained using the ferric ion reducing antioxidant power assay showed that cell disruption positively modulated the antioxidant capacity.
\end{abstract}

\section{Introduction}

Microalgae are known to contain a significant amount of nutrients that play important roles in cellular life; they include simple natural dyes and/or nutrients that exhibit a high level of biological activity [1-3]. After their incorporation in staple foods, microalgae may exert a substantial effect on health, with major benefits achieved when these foods are consumed regularly. Nonetheless, the cell wall integrity may significantly limit nutrient availability, since the structures of many microalgae species are covered with multiple layers of resistant cell walls that limit the release of cellular constituents [4]. The cell wall represents a natural barrier that results in the low bioavailability of intracellular molecules [5].

The controlled disruption of the cell wall (i.e. cell disruption) resulting from the downstream processes of biomass production (spray- drying or freeze-drying) or additional microalgal pretreatments has an important impact on the bioavailability of microalgae contents. The mechanisms by which these bioactives are released from the cells and altered during food processing and the final bioactivity of these substances with powerful health benefits are important questions to be answered. Cell rupture has been reported by several authors as a spectrum, beginning with minor damage and the release of internal biomolecules to complete cell disruption [6]. However, studies examining the effect of cell disruption on the bioactivity and physical properties of food products enriched with microalgae are scarce.

Many cell disruption methods are available, but disruption remains challenging since it depends on the cell wall structure and size and shape of the microalgae [4]. The complex cell wall structure must be disrupted to facilitate the liberation of the cellular contents. Extensive research has been analysed the disruption of microalgal cells [5].

\footnotetext{
* Corresponding author.

E-mail address: crnunes@gmail.com (M.C. Nunes).
} 
Depending on the aim of the pretreatment, chemical, physical and biological methods are employed, sometimes in combination, but an optimal method has not been established, even for biofuel production [3]. Recently, current and promising methods have been reviewed [3,4,7-10]. Factors such as the yield, cost, quality, bioactivity, sustainability, environmental pollution and residues must be investigated to select the most appropriate method [1].

Physical methods have been generally used for cell wall disruption, as they potentially avoid chemical contamination and preserve most of the functionality of the intracellular biomolecules [3]. High-pressure homogenization with the French press is one of the first methods used to disrupt algal cells and has been applied to highly concentrated algal pastes. A microalgal suspension is pumped through a narrow orifice $(80-200 \mu \mathrm{m})$ in a valve under high pressure (138-400 MPa) [9]; therefore, the suspension flows radially across the valve, strikes an impact ring, is extruded through the valve and flows into a discharge hole [7]. Mechanical effects such as turbulence, shear stress and cavitation promote cell disruption. The efficiency of the process depends on the pressure at the valve and the suspension properties (viscosity, cell size, and cell concentration) [10]. The temperature, number of passes, the valve and orifice designs, and a medium flow rate affect the efficiency of the process. In addition, cooling is essential for heat-sensitive products [11].

The cell wall composition of the Chlorella genus exhibits a great diversity among species and strains, and depends on the growth conditions and life stage of the cell $[5,9]$. Generally, the inner cell wall layer has high cellulose and hemicellulose contents, both of which are structural polysaccharides. Some authors described the presence of algaenan in the outer cell wall, which is a highly resistant aliphatic polymer [9]. Bernaerts et al. [12] studied the rheological properties of aqueous microalgal suspensions after mechanical and thermal processing. These authors indicated that the effects of subsequent thermal processing on the microstructure, viscoelastic properties and flow behaviour are determined by the previous mechanical treatment, since the thermal process enhances interactions between the released cell compounds. The authors suggested that Chlorella vulgaris would be used in applications as functional ingredient in food following mechanical and/ or thermal processing.

In the last few years, our research group published studies describing innovative and healthy products enriched with microalgae biomass, based on different food systems, e.g., emulsions [13], gels $[14,15]$, pasta $[16,17]$ and cookies $[18,19]$. The use of $C$. vulgaris as a food ingredient has been reported to be a promising method to enrich a staple food, such as bread, with bioactive compounds [20]. The possibility of adding a microalgal biomass to food depends on the type and intensity of processing (e.g., thermal and mechanical), food system (e.g., emulsion, gel, or foam) and interactions with other food molecules. Microalgae are exceptional sources of several components with important bioactivities that will potentially affect the food structure, depending on the biomass composition of each microalgal species $[11,21]$.

The present study proposes to explore the potential of a microalgal biomass to increase the nutritional quality of bread, while maintaining its high sensory quality. A biomass pretreatment was applied to promote the controlled release of the active compounds through cell wall disruption. A fresh C. vulgaris biomass was pre-processed using highpressure homogenization. The morphological changes in the cells were observed using flow cytometry. Doughs prepared with the addition of microalgae $(1.0 \mathrm{~g}$ of $\mathrm{Cv} / 100 \mathrm{~g}$ of flour $+\mathrm{Cv})$ were characterized by penetration and extensibility tests in a texturometer and by frequency sweep tests in a rheometer. The texture and colour of the breads were evaluated by comparing breads prepared with a fresh $C$. vulgaris biomass, fresh biomass subjected to disruption, and commercial powder (spray-dried product). Therefore, the effect of disruption on the antioxidant capacity of the bread was studied.

\section{Materials and methods}

\subsection{Materials}

The suspension of a C. vulgaris freshwater biomass $(0.88 \mathrm{~g} / \mathrm{L})$ was supplied by Allmicroalgae Company (Pataias, Portugal). The commercial C. vulgaris spray-dried powder ( $7.4 \%$ moisture) from the same company (L201510134 batch) was also used and contained the following nutritional components: $55.7 \mathrm{~g}$ of protein/100 g, $5.1 \mathrm{~g}$ of carbohydrates $/ 100 \mathrm{~g}$ and $5.2 \mathrm{~g}$ of fat/100 g. C. vulgaris is approved as a food-grade organism by the European Food Safety Authority.

Bread was prepared with commercial wheat flour (Granel T65, Portugal) with a minimum of $8.0 \%$ gluten (dry matter), distilled water, dehydrated yeast (Fermipan, Lallemand Iberia, Portugal), white crystalline saccharose (Sidul, Portugal), sea salt and the emulsifier SSLE481-sodium stearoyl-2 lactylate (Puratos, Portugal), according to a previously optimized formulation [20].

\subsection{Cell disruption}

The biomass sample $(0.88 \mathrm{~g} / \mathrm{L})$ was fed into the French press, an ultrahigh-pressure homogenizer (Stansted S-P CH-10, U.K.), using an operating pressure of $340 \mathrm{MPa}$ and 1 and 4 passages. The temperature was maintained at a value less than $35{ }^{\circ} \mathrm{C}$ using an internal cooling unit to minimize compound deterioration.

The flow cytometry analysis of suspensions of $C$. vulgaris, which are chlorophyll-rich cells, was performed using a CyFlow Space (SysmexPartec, Germany) flow cytometer with the True Volumetric Absolute Counting capability and equipped with a blue solid-state laser $(20 \mathrm{~mW}$ at $488 \mathrm{~nm}$ ). The equipment also contained four optical filters and detectors: 536/40 nm (FL1 green fluorescence), $575 \mathrm{~nm}$ (FL2 orange fluorescence), 610/30 nm (FL3 red fluorescence) and $675 \mathrm{~nm}$ (FL4 far red fluorescence).

One of the great advantages of flow cytometry is the possibility to perform a simultaneous multiparameter analysis of the physical and/or chemical properties of single cells. These properties include the cell size and granularity (intracellular complexity) that are measured by forward scatter (FSC) and side scatter (SSC), respectively. Fluorescence detection (using various detectors, e.g., FL1 or FL4) allows the assessment of cells, natural autofluorescence and any cell property with which a fluorescence dye might be associated [22].

Data acquired using flow cytometry are presented as monoparameter histograms (frequency distributions), dual parameter histograms and dot plots. While one-parameter histograms present the number of cells or particles (y-axis) $v s$ the scattering or fluorescence intensity (x-axis), dual parameter histograms are suitable to establish correlations between two parameters [23].

During data acquisition, gains were set to a specific and adequate value that was maintained throughout all analyses. Logarithmic amplification was chosen and, as microalgae possess endogenous fluorescing pigments (chlorophylls) that are detectable as red autofluorescence, the trigger was set on red fluorescence (FL4) to exclude any cell debris. The flow rate was adjusted to acquire $<2000$ events/s, and approximately 25,000 microalgal cell events were acquired for each sample. Microalgal populations were identified from an FSC $v s$ SSC dot plot and are presented on FL1 vs FL3 and FL4 vs FL3 dot plots.

The software used for data acquisition was Partec FlowMax (version 2.7), while data were analysed using FlowJo software (version 10.0.7, Tree Star).

A strategy based on double labelling with Syto9 and propidium iodide (L7012 Molecular Probes, Thermo Fisher Scientific) was used to detect damaged or permeabilized cell membranes with flow cytometry. Syto9 is a fluorochrome with a weak affinity for nucleic acids that diffuses passively through the membranes of most cells and is therefore used to label (FL1 - green fluorescence) all cells (permeabilized and non-permeabilized). Propidium iodide, an intercalating agent that 
inserts between nucleic acid bases, only penetrates cells with damaged membranes, functioning as a marker of non-viable cells (FL3 - red fluorescence).

For each sample and dye, the test was performed in triplicate.

\subsection{Dough and bread preparation}

Wheat flour water absorption was determined using the farinograph test (AACC 54-21.02) in a Brabender instrument (Germany), $61.8 \%$ at a $14 \%$ moisture basis. A Control without the microalgal biomass was prepared using $4.0 \mathrm{~g}$ of yeast, $1.7 \mathrm{~g}$ of salt, $1.0 \mathrm{~g}$ of sugar and $0.5 \mathrm{~g}$ of emulsifier per $100 \mathrm{~g}$ of wheat flour and $61.8 \mathrm{~g}$ of distilled water [20]. The breads with the $C$. vulgaris biomass were prepared replacing $1.0 \mathrm{~g}$ of flour with $C$. vulgaris/100 g. Raw and disrupted (340 MPa, 1 passage) microalgal suspensions $(0.88 \mathrm{~g} / \mathrm{L})$ were concentrated in a centrifuge at $8000 \mathrm{rpm}$ for $5 \mathrm{~min}$ at $5{ }^{\circ} \mathrm{C}$ and incorporated in breads as concentrates ( $0.88 \mathrm{~g}$ of dry cells dispersed in $40 \mathrm{~mL}$ of distilled water). The commercial C. vulgaris powder was also used for comparison, and its moisture content was considered when calculating the amount of water to be added.

Doughs were prepared using the procedure reported by Graça et al. [20]. A mixture of the solid ingredients with water was prepared in duplicate for each formulation using a current procedure for bread production. First, the yeast was activated with warm water in the thermo-processor cup (Bimby-Vorwerk, France, 30 s, position 3). Solid ingredients were added to this mixture, homogenized for $60 \mathrm{~s}$ at position 6 and subsequently kneaded for $120 \mathrm{~s}$. The dough $(30 \mathrm{~g})$ was placed in cylindrical containers $(6 \mathrm{~cm}$ diameter $\times 5 \mathrm{~cm}$ height), followed by fermentation for $60 \mathrm{~min}$ at $37^{\circ} \mathrm{C}$ in an electric oven (Arianna XLT133, Italy). The dough was baked at $160{ }^{\circ} \mathrm{C}$ for $20 \mathrm{~min}$. Breads were analysed after cooling.

\subsection{Texture, rheology and colour of dough and breads}

Doughs were characterized using empirical rheology methods in a texturometer (penetration and extensibility tests) and using fundamental small amplitude oscillatory stress rheology through frequency sweeps after fermentation.

After fermentation at $37{ }^{\circ} \mathrm{C}$ for $60 \mathrm{~min}$, doughs were characterized in a texturometer TA.XTplus equipped with a load cell of $5 \mathrm{~kg}$ (Stable MicroSystems, UK) using the Texture Profile Analysis in penetration mode (cylindrical probe with a $10 \mathrm{~mm}$ diameter, $14 \mathrm{~mm}$ distance, $5 \mathrm{~s}$ of waiting time and $1 \mathrm{~mm} \cdot \mathrm{s}^{-1}$ of crosshead speed). For each sample, the test was repeated at least four times at $20 \pm 1{ }^{\circ} \mathrm{C}$.

For the uniaxial extension tests, the SMS/Kieffer Dough and Gluten Extensibility Rig for the TA.XTplus was used, as described by Buresová et al. [24], with some modifications. The dough was moulded into rolls and placed on the Teflon mould, forming test pieces with a length of $5 \mathrm{~cm}$. The doughs were tested after resting for $10 \mathrm{~min}(\mathrm{t} 0)$ and $60 \mathrm{~min}$ (t60) at $30^{\circ} \mathrm{C}$. The force required to stretch the sample was recorded as a function of time using a test speed of $1.0 \mathrm{~mm} \cdot \mathrm{s}^{-1}$ and distance of $70 \mathrm{~mm}$. The peak force - resistance to extension $\mathrm{R}(\mathrm{N})$, distance corresponding to this peak - extensibility $\mathrm{E}(\mathrm{mm})$, and ratio number R/E $\left(\mathrm{N} \cdot \mathrm{mm}^{-1}\right)$ are the most important parameters. The test was repeated at least six times for each sample.

Viscoelastic properties of fermented doughs were assessed in a controlled stress rheometer (Haake Mars III - Thermo Scientific, Germany) with a UTC - Peltier system. A serrated parallel-plate sensor system (PP20) with a $2 \mathrm{~mm}$ gap was used. After kneading, the dough was shaped into small portions, placed in the oven to ferment for $60 \mathrm{~min}$, and then placed in the rheometer sensor and allowed to stabilize for $30 \mathrm{~min}$ before testing. Frequency sweeps were conducted at $5{ }^{\circ} \mathrm{C}$ to avoid fermentation during the tests, with oscillation frequencies ranging from 0.00628 to $628 \mathrm{rad} / \mathrm{s}$. A constant shear stress within the linear viscoelastic region of the material (10 Pa), which was previously determined by stress sweeps conducted at $6.28 \mathrm{rad} / \mathrm{s}$, was used in all measurements and the test was repeated at least three times. A thin layer of paraffin oil was applied to prevent moisture losses.

In the baked bread loaves, a texture profile analysis (cylindrical probe with a diameter of $10 \mathrm{~mm}, 8 \mathrm{~mm}$ distance, $5 \mathrm{~s}$ of waiting time and $1 \mathrm{~mm} \cdot \mathrm{s}^{-1}$ of crosshead speed) was also performed to investigate the impact of cell disruption on the bread structure. A slice with a $20 \mathrm{~mm}$ width was cut from the centre of each bread loaf, removing the top and bottom. Measurements were repeated at least six times for each bread.

The colour of dough and bread samples was measured using a Minolta CR-400 (Japan) colorimeter with standard illuminant D65 and a visual angle of $2^{\circ}$. The results are presented according to the CIELAB system: $\mathrm{L}^{*}$ - lightness ( 0 to 100 ), a* - greenness to redness ( -60 to 60 ), and $b^{*}$ - blueness to yellowness ( -60 to 60 ). The total colour difference between doughs and breads containing the microalgal biomass and the Control sample was calculated using the equation $\Delta \mathrm{E}^{*}=\left[\left(\Delta \mathrm{L}^{*}\right)^{2}+\left(\Delta \mathrm{a}^{*}\right)^{2}+\left(\Delta \mathrm{b}^{*}\right)^{2}\right]^{1 / 2}$. The measurements were replicated at least six times under artificial fluorescent light using a white standard $\left(\mathrm{L}^{*}=94.61, \mathrm{a}^{*}=-0.53\right.$, and $\left.\mathrm{b}^{*}=3.62\right)$.

\subsection{Bioactivity of breads}

To evaluate the antioxidant activity of breads, Samples were airdried at room temperature, crumbled fined into homogeneous powders using an electric blender, and shaken in $80 \%$ methanol at room temperature for $24 \mathrm{~h}$ to evaluate the antioxidant activity of breads. After filtration, the solvent was evaporated in vacuo. Dried extracts were dissolved in dimethyl sulfoxide to obtain $100 \mathrm{mg} / \mathrm{mL}$ stock solutions and stored at $-4{ }^{\circ} \mathrm{C}$ until the experiments were conducted.

The scavenging effect of bread extracts was determined using the DPPH (2,2-diphenyl-1-picryl-hydrazyl-hydrate) methodology [25]. Extraction solutions with a volume of $10 \mu \mathrm{L}$ each were added to $100 \mu \mathrm{L}$ ( $90 \mu \mathrm{mol} / \mathrm{L}$ ) of the DPPH solution in methanol, and the mixture was diluted with $190 \mu \mathrm{L}$ of methanol. In the Control, the extract was substituted with the same volume of solvent, and in the blank probe, only methanol $(290 \mu \mathrm{L})$ and the extract $(10 \mu \mathrm{L})$ were mixed. After 30 min, the absorbance was measured at $515 \mathrm{~nm}$. Three replicates were performed for each sample, and the mean values of the antioxidant capacity were reported as milligrams of Trolox equivalents per gram of dry weight (dw) of extract.

The reducing power of the bread extracts was determined using the ferric ion reducing antioxidant power (FRAP) assay [26] that was modified for 96 -well plates. The FRAP reagent was prepared by mixing $10 \mathrm{mmol} / \mathrm{L}$ 2,4,6-tripyridyl-s-triazine with $40 \mathrm{mmol} / \mathrm{L} \mathrm{HCl}, 0.02 \mathrm{~mol} / \mathrm{L}$ $\mathrm{FeCl}_{3}$ and acetate buffer, $\mathrm{pH} 3.6$ in a ratio of 1:1:10. The bread extract or ascorbic acid $(10 \mu \mathrm{L})$ was added to $290 \mu \mathrm{L}$ of FRAP reagent and the absorbance was measured at $593 \mathrm{~nm}$ after $6 \mathrm{~min}$. Three replicates were performed for each sample, and the mean values of reducing power were reported as milligrams of ascorbic acid equivalents per gram of dw of extract.

The total phenolic content (TPC) of bread extract was evaluated using the method reported by Fukumoto \& Mazza [27], which was customized for 96-well microplates. The bread extract or gallic acid $(30 \mu \mathrm{L})$ was added to $150 \mu \mathrm{L}$ of $0.1 \mathrm{~mol} / \mathrm{L}$ Folin-Ciocalteu reagent and mixed with $120 \mu \mathrm{L}$ of sodium carbonate $(7.5 \%)$ after $10 \mathrm{~min}$. The mixtures were incubated in the dark at room temperature for $2 \mathrm{~h}$, and then the absorbance was measured at $760 \mathrm{~nm}$. The TPC was reported as milligrams of gallic acid equivalents per gram of $\mathrm{dw}$ of extract, and corresponded to the mean value of triplicate tests.

\subsection{Statistical analysis}

The analysis of variance (one-way ANOVA) of the experimental data was performed using Origin Pro 8.0 software, followed by Tukey's test. The significance level was set to $95 \%(p<.05)$. 
A

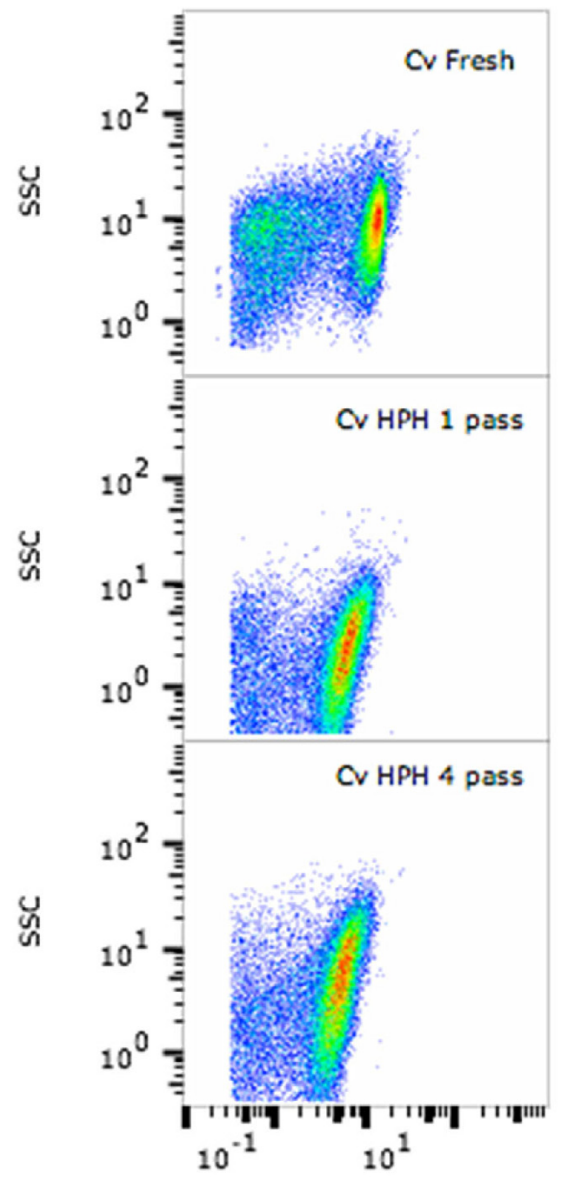

FSC
B

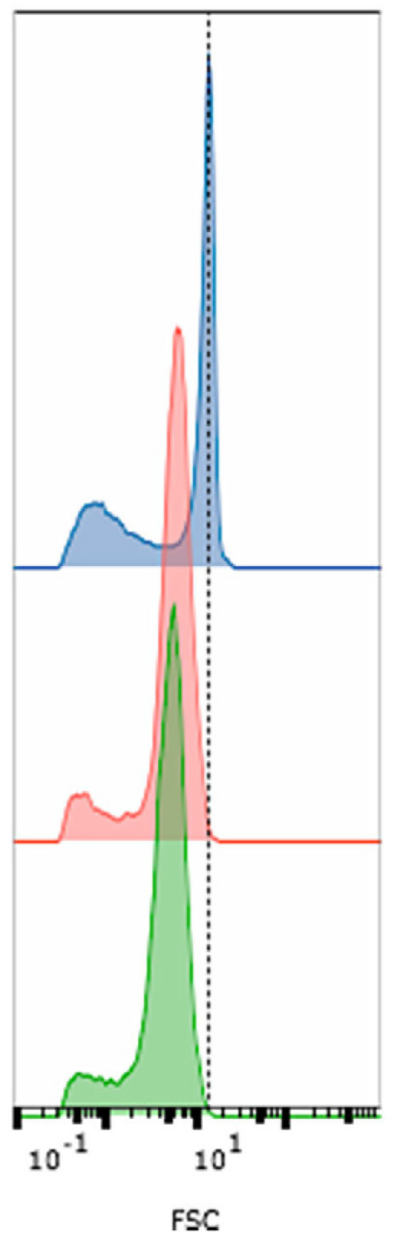

c

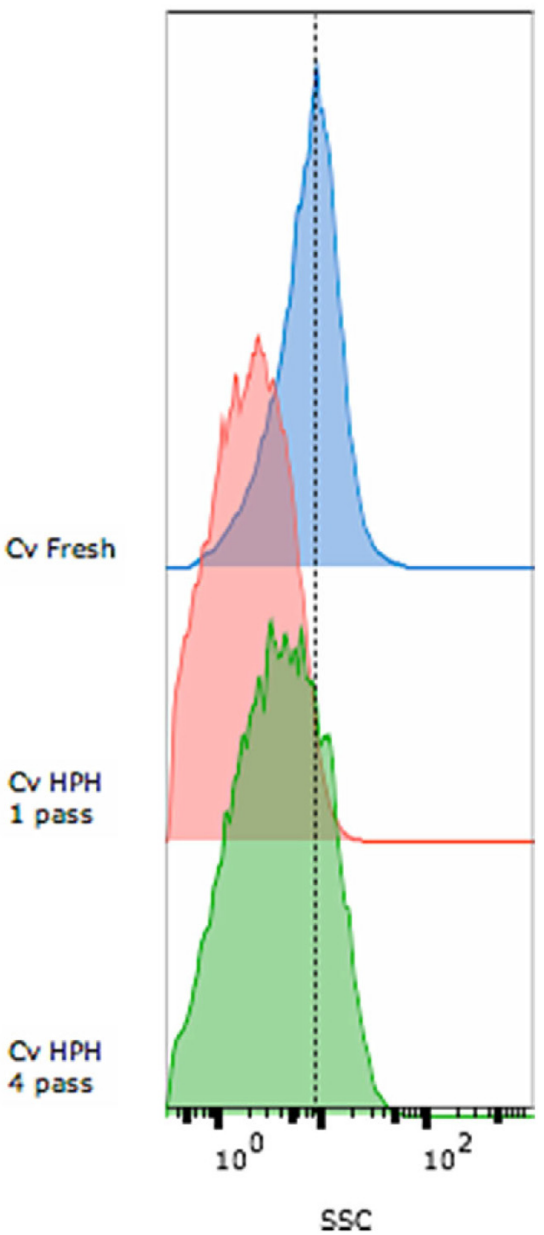

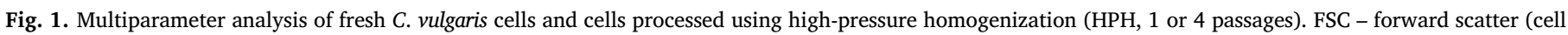

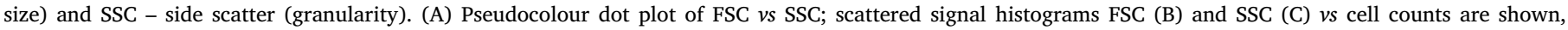
respectively. For each sample, the test was performed in triplicate.

\section{Results and discussion}

\subsection{Morphological changes in the cells}

Microalgal suspensions are complex systems of algal cells and cell debris dispersed in a continuous water phase with dissolved salts and biopolymers [12]. The most common skeletal polysaccharide is cellulose, which increases in thickness during maturation [28]. C. vulgaris cells are spherical structures with sizes ranging from 1 to $3 \mu \mathrm{m}$ [10].

Flow cytometry was used in combination with fluorescence microscopy to study the effect of the disruption of $C$. vulgaris cells using highpressure homogenization. This method was used by Günerken et al. [29] to estimate biomass release and the cell disruption yield of Chlorella sp.

Data from the first acquisition are presented in an FSC $v s$ SSC dot plot in which the population was properly identified and gated to eliminate artefacts or false events (Fig. 1A). From this gated population, 2 graphs were obtained: the FSC $v s$ cell count histogram (Fig. 1B) and SSC $v s$ cell count histogram (Fig. 1C). Cell counts decreased after the disruption treatment by approximately 33\% with 1 passage and $59 \%$ with 4 passages. This decrease in the number of cells was accompanied by a reduction in the cell size (Fig. 1B), as shown by the variation in the geometric mean values of FSC (Fig. 2) and complexity (Fig. 1C), although no differences were noticed in these cell parameters after 1 or 4 passages.

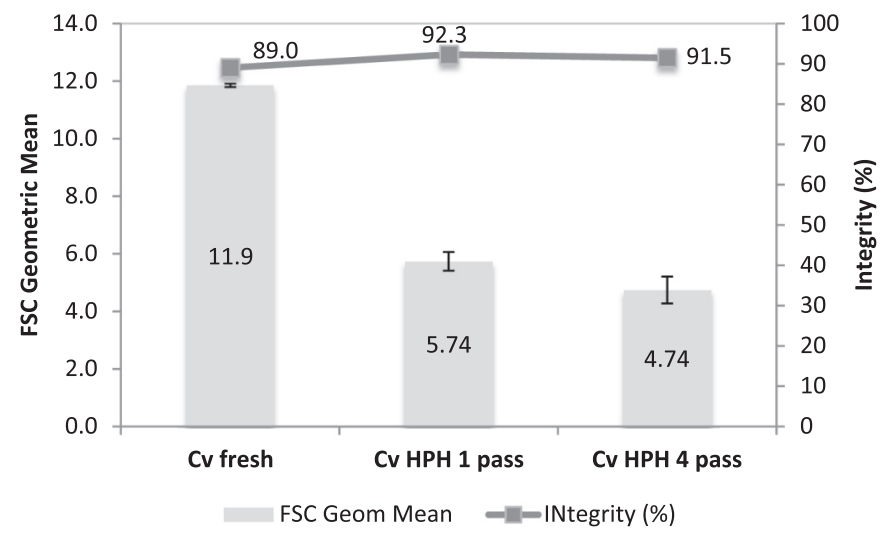

Fig. 2. FSC (forward scatter) geometric mean and cellular integrity obtained from the flow cytometry analysis of fresh $C$. vulgaris cells and cells processed using high-pressure homogenization (HPH, 1 or 4 passages). For each sample, the test was performed in triplicate. Error bars indicate the standard deviations of the triplicate measurements.

The effect of the disruption on the membrane permeabilization was analysed by labelling cells with Syto9 (green fluorescence - FL1, Fig. 3A) as a marker of all cells, propidium iodide (red fluorescence FL3, Fig. 3B) as a marker of permeabilized cells, and chlorophyll 
A

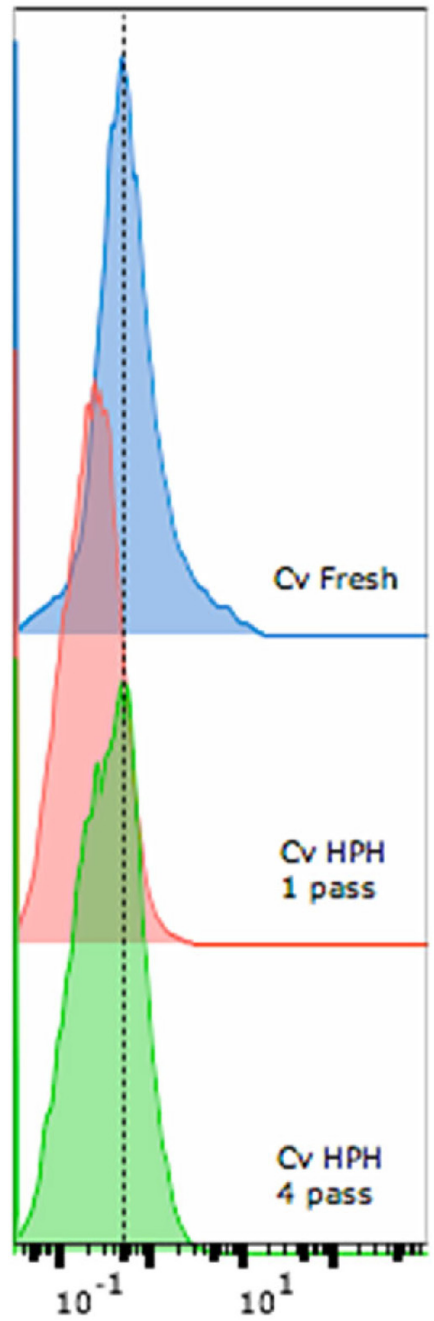

FL1
B

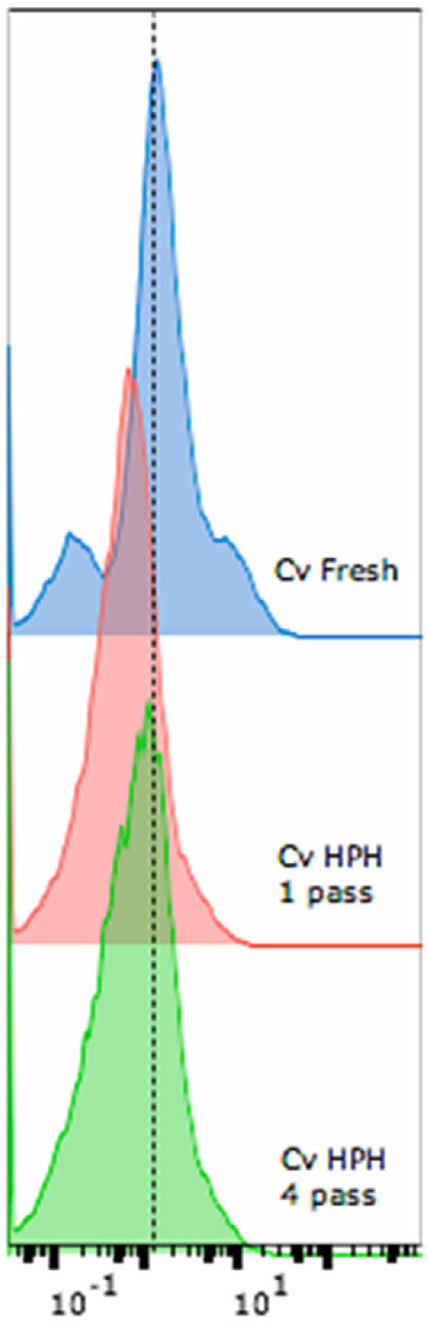

FL3
C

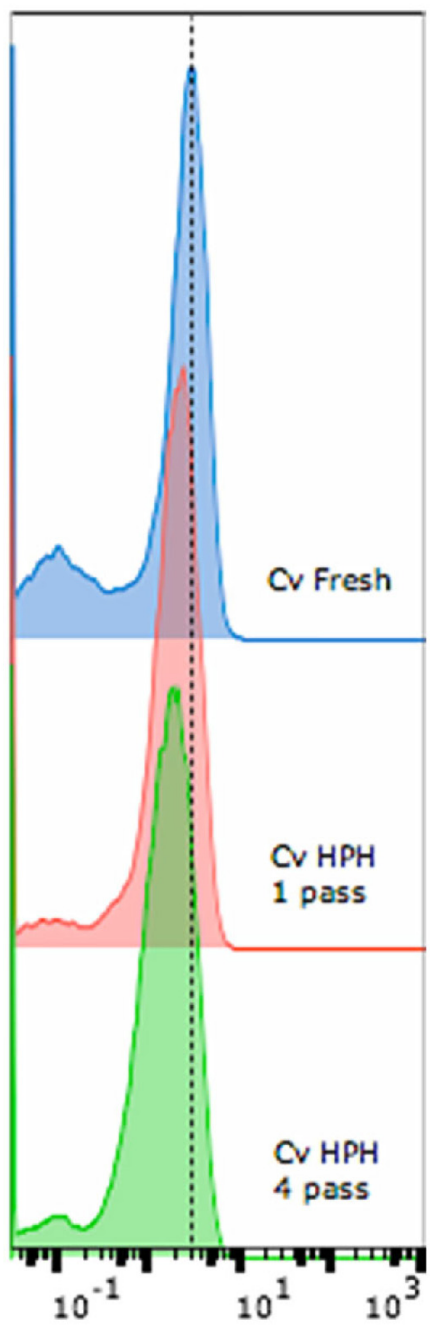

FL4

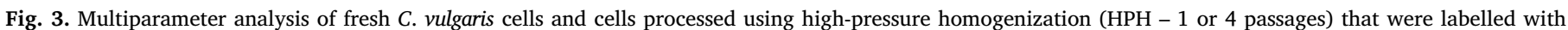

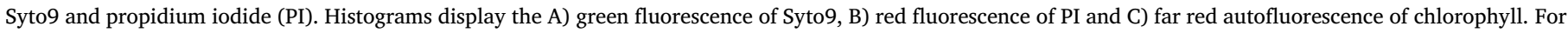

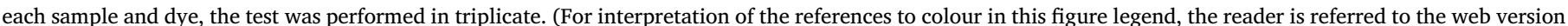
of this article.)

autofluorescence (far red fluorescence - FL4, Fig. 3C) as a marker of microalgae.

Two dot plots were also obtained from the gated population, FL1 vs FL3 (Fig. 4A) and FL4 vs FL3 (Fig. 4B), which were used to determine the level of cellular permeabilization based on a quadrant gating scheme that best fitted each population. The criterion chosen for the permeabilization assessment was the membrane integrity, as evidenced by cells that presented no or low red fluorescence (FL3) with either high or low green (FL1) or far red fluorescence (FL4). Based on the results, the larger cells were lysed and that the integrity of approximately $40 \%$ of the smaller cells remaining after disruption was not compromised (Figs. 2-4).

Some other authors studied the effect of high-pressure homogenization on microalgal cell disruption. Samarasinghe et al. [30] showed a reduction in the $N$. oculata cell count as the pressure (69-301 MPa) and number of passes through the homogenizer increased. The structures of five microalgae, including C. vulgaris, were investigated by Safi et al. [31] in order to evaluate the release of proteins from cells after the application of different cell disruption methods. The authors concluded that high-pressure homogenization $(270 \mathrm{~Pa})$ was the most efficient method. This method released approximately half of the protein, showing that more energy input is necessary to completely disrupt the microalgae macrostructure. Safi et al. [28] observed the disruption of the majority of $C$. vulgaris cells at $270 \mathrm{~Pa}$ and 2 passes, while some cells remained intact, and chloroplasts were also partially damaged. These results $[28,31]$ correspond to a higher degree of disruption than the level observed in our study (a 33\% reduction in the cell number after 1 passage and 59\% reduction after 4 passages at $340 \mathrm{~Pa}$ ). Spiden et al. [6] studied the effects of thermal and acidic treatments before high-pressure homogenization (84 MPa) on Chlorella cells to reduce the amount of energy required for disruption. Recently, Grossmann et al. [32] investigated the preparation of proteinrich extracts from different microalgae by applying minimal processing applications; the $C$. vulgaris cells were disrupted through high-pressure homogenization (180 MPa) and 9 passes were necessary to disrupt $99 \%$ of the cells.

Flow cytometry was not applied to the commercial Chlorella sample that was dehydrated by spray-drying during the downstream process. 
A

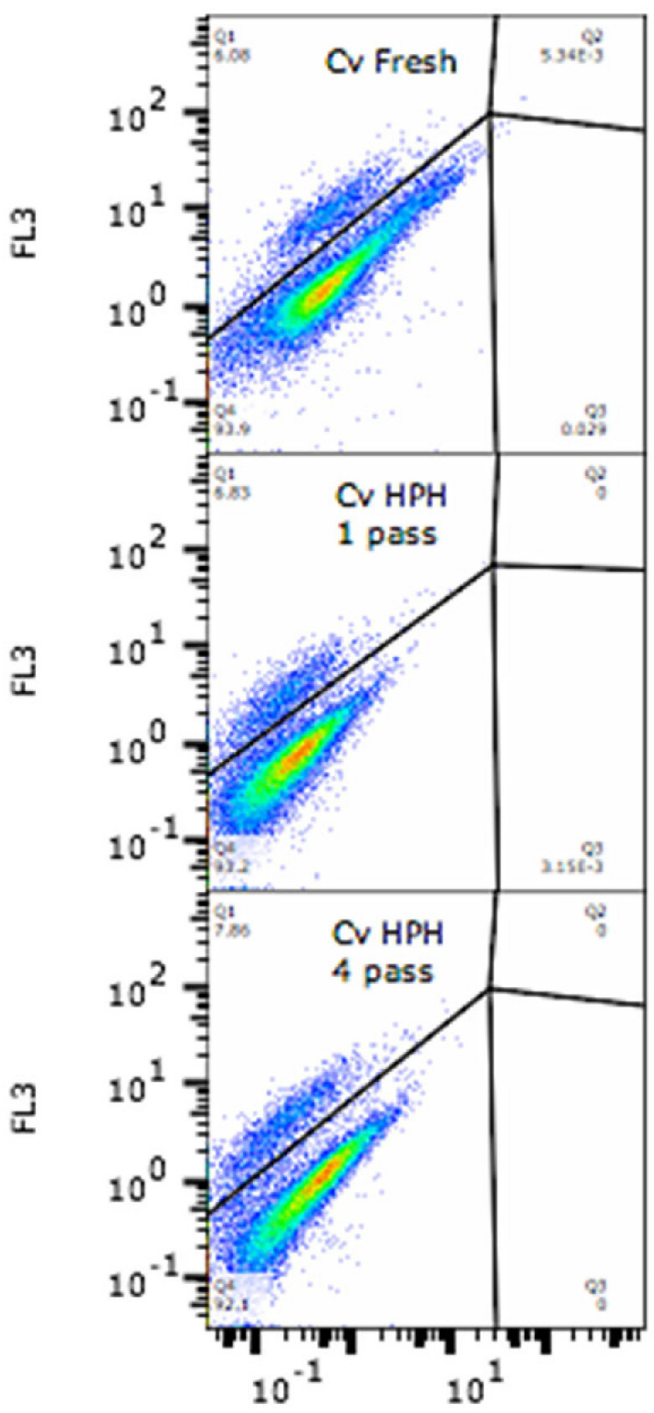

FL1

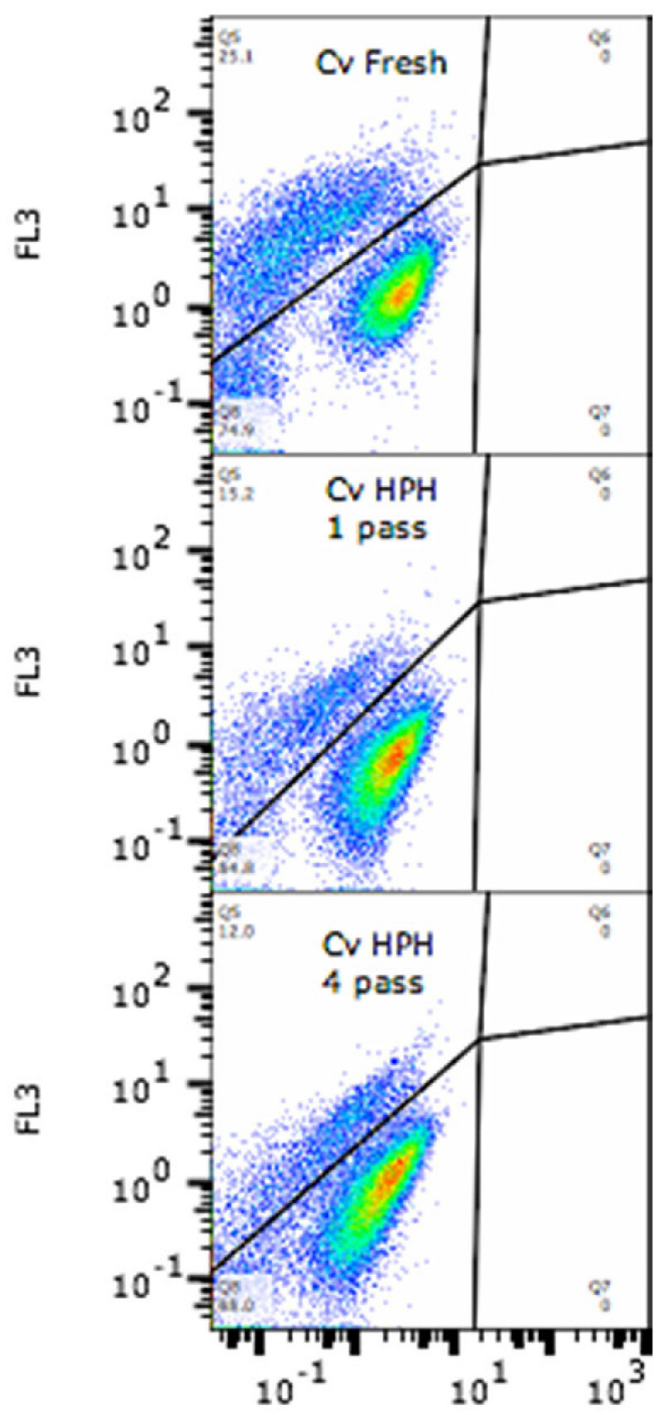

$\mathrm{FL} 4$

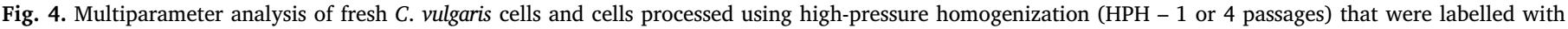

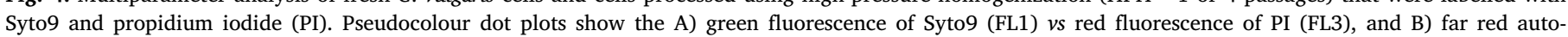

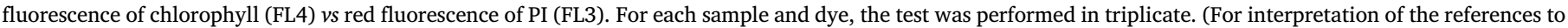
colour in this figure legend, the reader is referred to the web version of this article.)

However, Unterlander et al. [33] showed that lyophilization prior to lysis using a French press or other methods resulted in substantial increases in the soluble protein concentration and level of active enzymes from $C$. vulgaris. A small hole in the cell wall is sufficient to release the contents of the cells [34].

\subsection{Effects on the rheological and colour properties of wheat doughs and} breads

C. vulgaris is composed of proteins and cell wall polysaccharides, while lipids represent a smaller fraction. Relatively low levels of storage polysaccharides, such as starch and glycogen, are usually observed. Cell wall-related polysaccharides comprise different types of polymers, including cell wall polysaccharides and extracellular polymers, and potentially explain some of the techno-functional properties of the biomass [5].

In wheat dough, the gluten proteins build a network in which starch granules and gas bubbles are embedded. During proofing, the yeast produces $\mathrm{CO}_{2}$, decreasing the consistency of the dough. Both empirical and fundamental rheology methods allow the estimation of the technological behaviour of the dough and properties of the bread [35].

By examining the dough texture results, the firmness (Fig. 5A) of the Control dough was higher $(0.36 \mathrm{~N})$ than doughs containing the $C$. vulgaris biomass, and significant differences $(p<0.05)$ were observed when cell disruption was applied $(0.16 \mathrm{~N}$ for $\mathrm{Cv}$-Fresh and $0.26 \mathrm{~N}$ for $\mathrm{Cv}$-HPH and Cv-Commercial). Slight differences in the adhesiveness of the Control formulation containing $C$. vulgaris were observed, but no significant differences were obtained after cell disruption. A decrease in the resistance of a dough to extension (R) after microalgal biomass incorporation was observed in the extensibility tests, except for $\mathrm{Cv}$ Commercial, which presented a similar value to the Control at t0 and t60 (Fig. 5C). Cv-Fresh dough showed a greater extensibility (E) at t0 that was higher than the Control, but no significant differences $(p>.05)$ were observed between all doughs after fermentation 


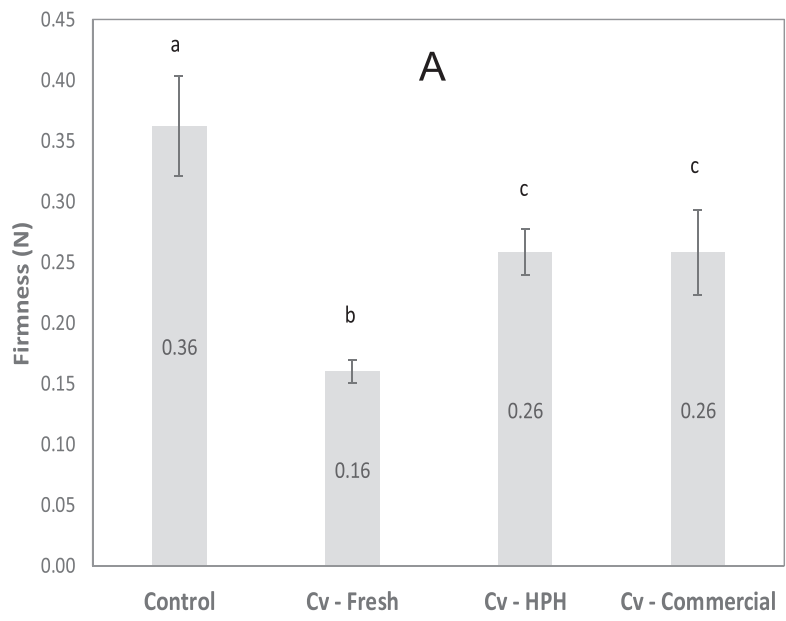

C

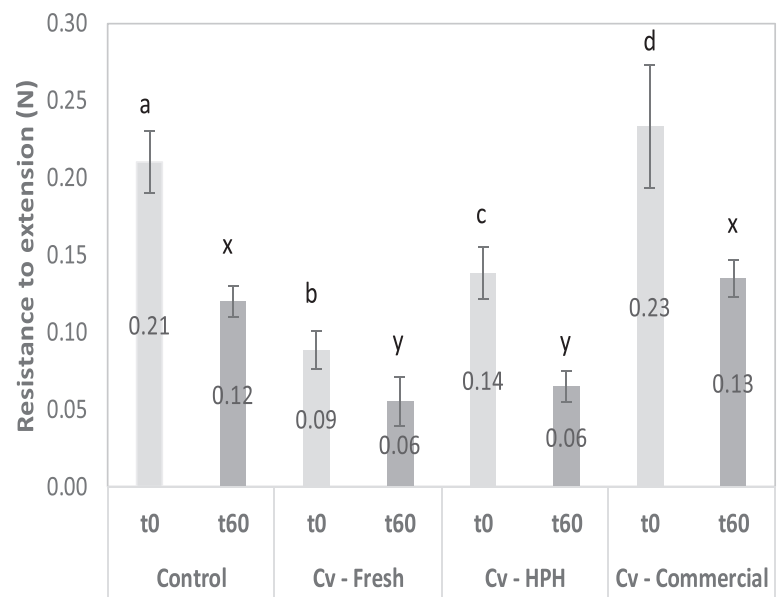

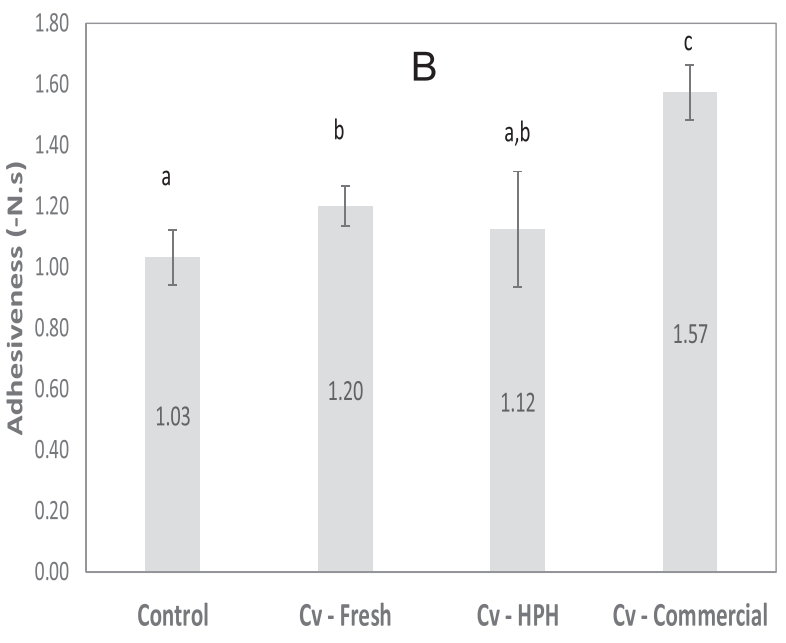

D

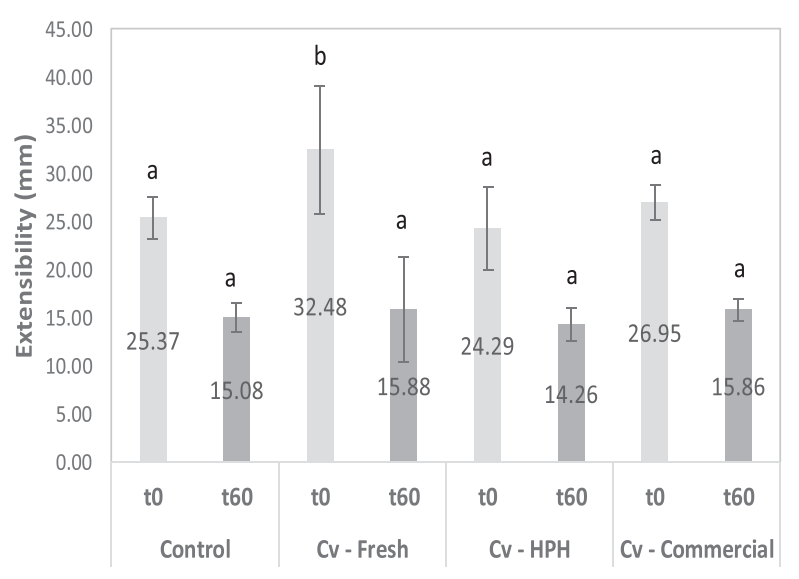

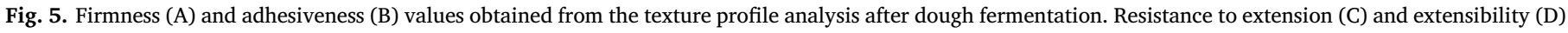

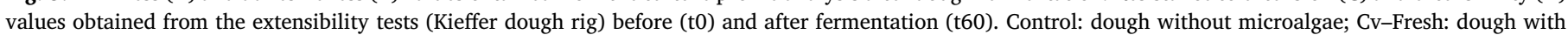

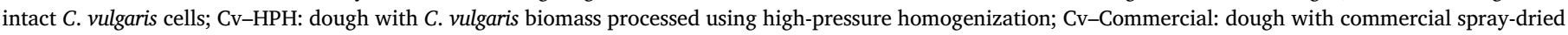

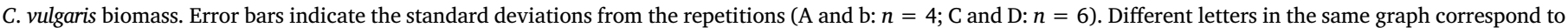
significant differences $(p<.05)$.

(Fig. 5D). The extensibility of the dough is very important due to its effect on the bread volume [35]. Values of $0.21 \mathrm{~N}$ for resistance to extension and $25.4 \mathrm{~mm}$ for extensibility of the Control dough (t0) were lower than the values of approximately $0.4-0.6 \mathrm{~N}$ and $30 \mathrm{~mm}$, respectively, obtained from wheat by other researchers [24,36]. Baking performance may be measured by assessing dough resistance and the stretching ratio, which is known as the R/E modulus. The loaves with fresh and disrupted microalgal cells presented lower R/E values than the Control, and the Control showed no significant differences $(p>.05)$ to the $\mathrm{Cv}$-Commercial loaves. Cell disruption exerted an effect on non-fermented doughs, with 2.82 and $5.94 \times 10^{-3} \mathrm{~N} / \mathrm{mm}$ for $\mathrm{Cv}$-Fresh and $\mathrm{Cv}-\mathrm{HPH}$, respectively, values that were lower than the value of $8.24 \times 10^{-3} \mathrm{~N} / \mathrm{mm}$ for the Control dough. Nevertheless, after fermentation (t60), the Cv-Fresh and $\mathrm{Cv}$-HPH doughs showed no significant differences $(\mathrm{p}>$.05).

Dynamic (oscillatory) tests in the rheometer measure the storage $\left(G^{\prime}\right)$ and the loss $\left(G^{\prime \prime}\right)$ moduli and their contributions to the viscoelastic behaviour. Dough is a highly viscoelastic material that rises during proofing, whereas a dough that is not elastic does not achieve a good volume [35]. Fermented doughs have a viscoelastic behaviour, with $\mathrm{G}^{\prime}$ higher than $\mathrm{G}^{\prime \prime}$, and both values depend on the frequency. A crossover of $G^{\prime}$ and $G^{\prime \prime}$ is observed at low frequencies (Fig. 6A). Thus, doughs exhibit a more viscous behaviour, but at high frequencies, polymers of the dough, mainly glutenins, generally reacted elastically, indicating that more bounds are involved in the mechanical response of the dough [37]. All the materials presented a similar level of structure, showing the same trends in the values for the loss tangent $\left(\tan \delta=\mathrm{G}^{\prime \prime} / \mathrm{G}^{\prime}\right)$ (Fig. 6B), but the magnitudes of $\mathrm{G}^{\prime}$ and $\mathrm{G}^{\prime \prime}$ decreased with $C$. vulgaris incorporation, consistent with the firmness values of the doughs obtained in the texture profile analysis. Based on these results, cell disruption exerted a limited effect on the dynamic viscoelastic properties of the dough, with a slight reinforcement of the structure, since the viscoelastic values of $\mathrm{Cv}-\mathrm{HPH}$ and $\mathrm{Cv}$-Commercial were higher than $\mathrm{Cv}$ Fresh.

During baking, dough increases in volume due to thermal gas expansion, and the gluten network denatures and retains starch granules that gelatinize during baking. Thus, the dough is converted into bread exhibiting a sponge-like soft crumb [35]. Crumb firmness (Fig. 7) was significantly $(p<.05)$ altered by the addition of the fresh microalgal biomass, with Control $(2.38 \mathrm{~N})>\mathrm{Cv}$-Fresh $(1.84 \mathrm{~N})$. Following disruption, the firmness of breads with $\mathrm{Cv}-\mathrm{HPH}$ and $\mathrm{Cv}$-Commercial cells was not significantly different $(p>.05)$ from the Control, but both values were higher than $\mathrm{Cv}$-Fresh, confirming the positive effect of the microalgae pretreatment on the bread texture.

According to Batista et al. [19], the addition of $2 \%$ commercial microalgae biomass does not affect the texture of a wheat cookie, whereas an increase in the $C$. vulgaris content to $6 \%$ causes a significant increase in hardness. The results presented here are also consistent with 

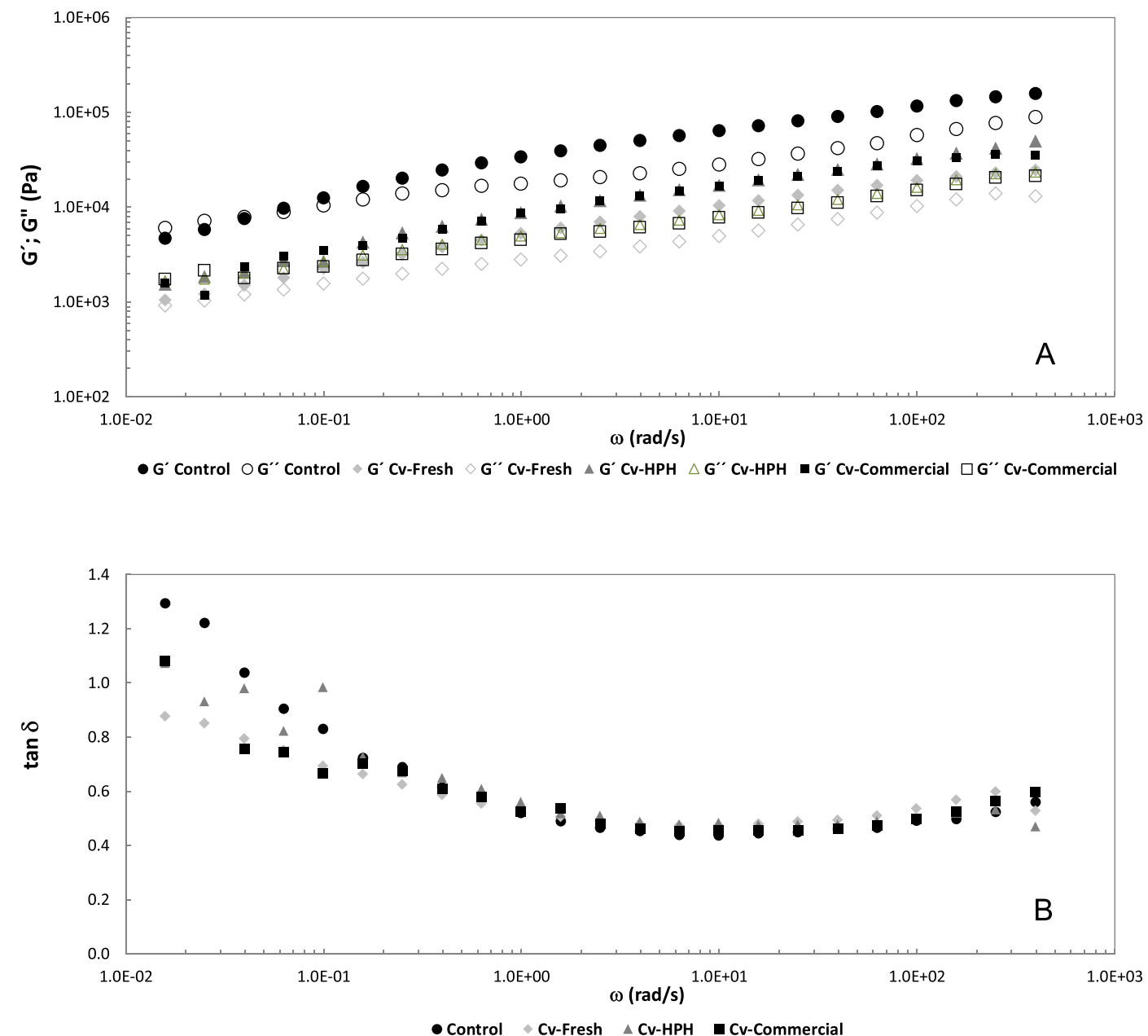

Fig. 6. Viscoelastic moduli $\mathrm{G}^{\prime}$ and $\mathrm{G}^{\prime \prime}(\mathrm{A})$ and $\tan \delta$ (B) as a function of frequency obtained after dough fermentation. $\mathrm{G}^{\prime}$ (storage modulus - filled symbol), $\mathrm{G}^{\prime \prime}$ (loss modulus - open symbol). Control: dough without microalgae; $\mathrm{Cv}-$ Fresh: dough with intact $C$. vulgaris cells; Cv-HPH: dough with $C$. vulgaris biomass processed using high-pressure homogenization; $\mathrm{Cv}-$ Commercial: dough with commercial spray-dried $C$. vulgaris biomass. For each sample, the test was performed in triplicate, and the most representative curve for each sample is presented.

previous studies analysing wheat bread that did not show substantial effects of commercial dried C. vulgaris on firmness at levels of $1 \%$ to $5 \%$ [20] and by other microalgae species at $1.5 \%$ [38]. Similar conclusions were obtained from gluten-free bread. The crumb firmness was not affected by the incorporation of up to $4 \%$ of Spirulina cyanobacteria [39] or $2 \%$ brown macroalgae [40].

In addition to cell disruption, an important issue to address when using microalgae as a food ingredient is the level of technological processing applied (e.g., temperature, pressure, and $\mathrm{pH}$ ). In this context, Bernaerts et al. [12] observed low values of $\mathrm{G}^{\prime}$ for $C$. vulgaris suspensions upon high-pressure homogenization at $\mathrm{pH} 6$, but a subsequent thermal treatment resulted in a substantial increase in $\mathrm{G}^{\prime}$ that corresponded to the formation of a network structure. Indeed, thermal processing might damage cell walls and result in the solubilization of the components and agglomeration/aggregation of cell debris. As the $C$. vulgaris biomass contains a high protein content, this result was ascribed to aggregation of the denatured proteins [12] and to the presence of polysaccharides. Therefore, cell disruption promotes the release of intracellular products, including proteins and polysaccharides, and the subsequent baking process imparts structural modifications to breads. This finding may explain the differences in the texture and rheology of Cv-Fresh compared to Cv-HPH and Cv-Commercial. Further studies are necessary to clarify the protein and polysaccharide contents in the released material, since these components might affect the structures of the dough and bread.
The results obtained for the dough and bread colour parameters are presented in Table 1. A reduction in lightness $\left(\mathrm{L}^{*}\right)$ and an increase in yellowness ( $\left.\mathrm{b}^{*}\right)$ and greenness ( $\mathrm{a}^{*}$, in modulus) with the addition of microalgal biomass were observed. These results are related to the high chlorophyll content of $C$. vulgaris. Cell disruption through high-pressure homogenization did not exert a significant effect $(p>.05)$ on the bread colour, while Cv-Fresh dough presented higher negative $a^{*}$ (green hue) than the Cv-HPH dough. The total colour difference $\Delta \mathrm{E}^{*}$ between Cv-Fresh and Cv-HPH was equal to 2.8 for the doughs and 0.5 for breads. Some authors consider that a total colour difference below 1 is not detected by the human eye and not appreciated for values ranging from $1<\Delta \mathrm{E}^{*}<3$; thus, $\Delta \mathrm{E}^{*}>3$ is set as the threshold value for obvious colour differences [41]. Other researchers stated than the human eye is only able to differentiate colours when the total colour difference $\Delta E^{*}>5$ [42]. A large colour difference of 19.0 and 12.5 was observed between doughs and breads in which $\mathrm{Cv}$-Fresh and $\mathrm{Cv}$ Commercial were incorporated, respectively, due to the effect of the spray-drying process.

\subsection{Effect on bread bioactivity}

Microalgae are one of the most economical and interesting sources of natural molecules with strong antioxidant properties. Green algae present primary carotenoids that are dispersed within the chloroplasts and the chlorophylls $[21,43]$. The green microalgal Chlorella possesses a 


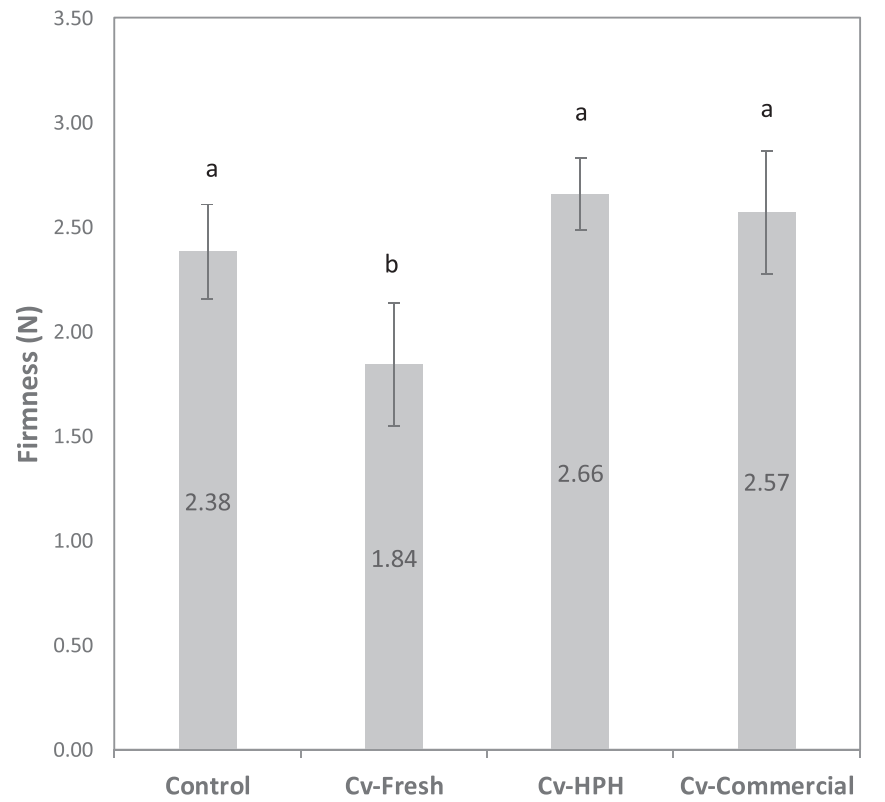

Fig. 7. Values of firmness obtained from texture profile analysis of breads. Control: bread without microalgae; $\mathrm{Cv}-$ Fresh: bread with intact $C$. vulgaris cells; $\mathrm{Cv}-\mathrm{HPH}$ : bread with $C$. vulgaris biomass processed using high-pressure homogenization; $\mathrm{Cv}-$ Commercial: bread with commercial spray-dried $C$. vulgaris biomass. Error bars indicate the standard deviations of the repetitions $(n=6)$. Different letters correspond to significant differences $(\mathrm{p}<.05)$.

\section{Table 1}

CIELAB colour parameters of doughs and breads. Control: bread without microalgae; $\mathrm{Cv}-$ Fresh: bread with intact $C$. vulgaris cells; $\mathrm{Cv}-\mathrm{HPH}$ : bread with $C$. vulgaris biomass processed using high-pressure homogenization; Cv-Commercial: bread with commercial spray-dried C. vulgaris biomass. Error bars indicate the standard deviations of the repetitions $(n=6)$. Different letters in the same column correspond to significant differences $(p<.05)$.

\begin{tabular}{|c|c|c|c|c|c|c|}
\hline & \multicolumn{3}{|c|}{ Dough Colour } & \multicolumn{3}{|c|}{ Crumb colour } \\
\hline & $\mathrm{L}^{*}$ & $a^{*}$ & $b^{*}$ & $\mathrm{~L}^{*}$ & $a^{*}$ & $b^{*}$ \\
\hline Control & $79.68^{a}$ & $0.82^{\mathrm{a}}$ & $20.16^{\mathrm{a}}$ & $66.58^{a}$ & $-0.39^{a}$ & $14.40^{\mathrm{a}}$ \\
\hline Cv-Fresh & $53.77^{\mathrm{b}}$ & $-14.79^{b}$ & $29.20^{b}$ & $49.24^{b}$ & $-3.35^{b}$ & $23.77^{b}$ \\
\hline $\mathrm{Cv}-\mathrm{HPH}$ & $55.98^{c}$ & $-13.97^{c}$ & $27.66^{c}$ & $48.85^{b}$ & $-3.43^{b}$ & $23.42^{b}$ \\
\hline Cv-Commercial & $67.55^{d}$ & $-6.13^{d}$ & $19.39^{a}$ & $60.94^{c}$ & $-2.90^{\mathrm{c}}$ & $19.44^{\mathrm{c}}$ \\
\hline
\end{tabular}

high antioxidant activity due to the high contents of chlorophylls (a and b) and vitamin E [19,44]. Batista et al. [21] reported a total pigment content of $1.2 \%$ for $C$. vulgaris, with lutein/zeaxanthin representing the main carotenoids and both chlorophyll a and b were present.

The antioxidant capacity of microalgal-enriched breads was tested using the DPPH and FRAP methods (Fig. 8A and B). Compared with the Control bread (4.28 mg. $\mathrm{g}^{-1}$ Trolox equivalents and $4.49 \mathrm{mg} \cdot \mathrm{g}^{-1}$ ascorbic acid equivalents), the incorporation of the fresh microalgal biomass led to an increase in the antioxidant capacity of the breads (9.65 $\mathrm{mg} \cdot \mathrm{g}^{-1}$ Trolox equivalents and $7.77 \mathrm{mg} \cdot \mathrm{g}^{-1}$ ascorbic acid equivalents). The bread with disrupted Chlorella cells, which were pretreated with high-pressure homogenization, showed a higher FRAP antioxidant capacity (11.63 mg.g ${ }^{-1}$ ascorbic acid equivalents) that differed from the value obtained using the DPPH method $\left(9.32 \mathrm{mg} \cdot \mathrm{g}^{-1}\right.$ Trolox equivalents), which is similar to the $\mathrm{Cv}$-fresh bread. Even upon baking, the antioxidant activity of these breads is interesting. A greater loss of microalgae antioxidants $\left(2.57 \mathrm{mg} \cdot \mathrm{g}^{-1}\right.$ Trolox equivalents and $5.9 \mathrm{mg} \cdot \mathrm{g}^{-1}$ ascorbic acid equivalents) was observed in the bread with the commercial spray-dried $C$. vulgaris biomass. This loss is potentially related to the industrial downstream operations, including thermal treatments, namely, pasteurization and spray-drying.
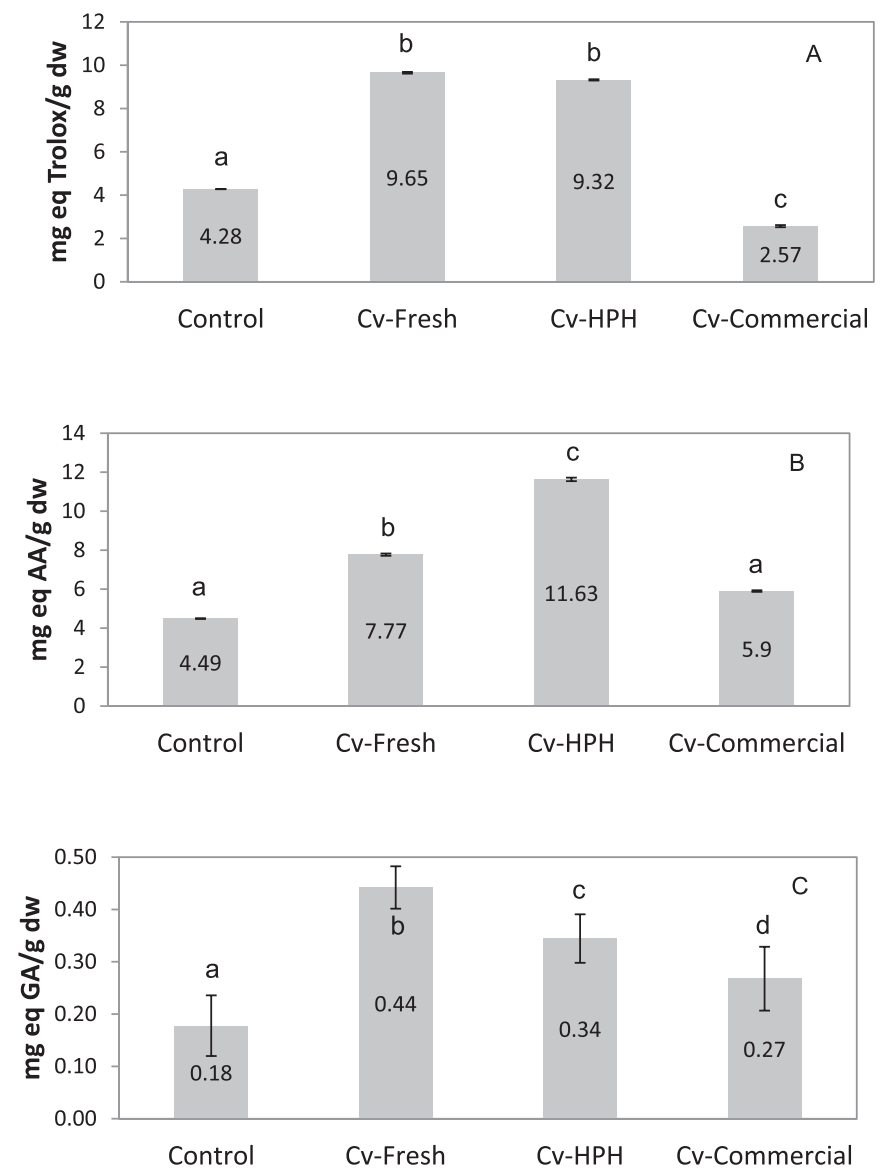

Fig. 8. A) Antioxidant capacity measured using the DPPH (2,2-diphenyl-1-picryl-hydrazyl-hydrate; $\mathrm{mg} \cdot \mathrm{g}^{-1}$ Trolox equivalents) assay and B) FRAP assay (ferric ion reducing antioxidant power; $\mathrm{mg} \cdot \mathrm{g}^{-1}$ ascorbic acid (AA) equivalents) and C) total phenolic content (mg. $\mathrm{g}^{-1}$ gallic acid (GA) equivalents) of breads enriched with $1.0 \mathrm{~g}$ of $C$. vulgaris $/ 100 \mathrm{~g}$ of flour $+\mathrm{Cv}$ and Control breads. $\mathrm{dw}-$ dry weight. Control: bread without microalgae; $\mathrm{Cv}-$ Fresh: bread with intact $C$. vulgaris cells; $\mathrm{Cv}-\mathrm{HPH}$ : bread with a $C$. vulgaris biomass processed using highpressure homogenization; $\mathrm{Cv}-\mathrm{Commercial}$ : bread with a commercial spraydried C. vulgaris biomass. Error bars indicate the standard deviations of the repetitions $(n=3)$. Different letters in the same graph correspond to significant differences $(p<.05)$.

In fact, an important issue to address when using microalgae as a food ingredient is the level of technological processing applied. The effect of baking on the antioxidant activity of cookies enriched with different types of microalgae was studied by Batista et al. [19]. Values of 7.0 to $9.5 \mathrm{mmol}$ of Trolox equivalent antioxidant capacity per $\mathrm{kg}$ were obtained in cookies with $2 \%$ alga. Zouari et al. [45] and Rodríguez et al. [46] studied the effect of enrichment with Arthrospira platensis on the free radical scavenging activity, and although pasta processing and cooking exerted some effects, the addition of the cyanobacteria increased the antioxidant activity of pasta products. Research on bread products with microalgae is scarce; the only study focused on the antioxidant activity of bread supplemented with algae was published by Rózylo et al. [40]. The authors determined the effect of brown macroalgae on gluten-free bread and observed increased antioxidant activity. A recent study by Shen et al. [47] examining the Maillard Reaction manipulation to maximize the antioxidant potential of white bread products might explain the values obtained for the Control bread. These authors reported that breads containing sucrose or fructose, such as our bread, had good antioxidant capacities.

Phenolic compounds, including simple phenols, flavonoids, phenylpropanoids, tannins, lignins and phenolic acids, are regarded as some of the most important classes of natural compounds with many 
health benefits, including antioxidant potential $[19,48]$. The addition of the microalgal biomass ( $1.0 \mathrm{~g}$ of $C$. vulgaris $/ 100 \mathrm{~g}$ of flour $+\mathrm{Cv}$ ) resulted in an increase in the total phenolic content (TPC) (Fig. 8C), which was $0.18 \mathrm{mg} \cdot \mathrm{g}^{-1}$ gallic acid equivalents in the Control bread and $0.44 \mathrm{mg} \cdot \mathrm{g}^{-1}$ in the bread containing fresh $C$. vulgaris. As expected, the bread prepared with the commercial $C$. vulgaris powder presented a lower TPC that was similar to the Control $\left(0.27 \mathrm{mg} \cdot \mathrm{g}^{-1}\right.$ gallic acid equivalents). However, cell disruption did not increase the TPC of Cv$\mathrm{HPH}$ bread (0.34 $\mathrm{mg} \cdot \mathrm{g}^{-1}$ gallic acid equivalents). TPC values were lower than the values reported by Rózylo et al. [40] for gluten-free bread containing brown algae. Based on these findings, we concluded that phenolic compounds that were released from the disrupted cells did not exert a significant effect on the antioxidant potential of the tested breads, since some other biocompounds made substantial contributions to this biological activity.

\section{Conclusions}

Based on the findings of the present study, $C$. vulgaris can be used as an innovative ingredient to enhance the nutritional properties and technological behaviour of bread, and cell disruption can be applied to improve its potential. Differences between breads produced with raw and disrupted microalgal cells were observed. The thermal processing of breads during baking after a pretreatment of microalgal suspensions using high-pressure homogenization should enhance interactions within the released cell material. Disruption affected the rheological properties of the doughs and breads (C. vulgaris $1 \% \mathrm{w} / \mathrm{w}$ ) by reinforcing the structure. The antioxidant capacity (ferric ion reducing antioxidant power) of breads containing the pretreated biomass was higher than breads containing intact cells.

\section{CRediT authorship contribution statement}

M. Cristiana Nunes: Data curation, Formal analysis, Conceptualization, Writing - original draft, Writing - review \& editing. Carla Graça: Data curation. Sanja Vlaisavljević: Investigation, Formal analysis, Writing - original draft, Writing - review \& editing. Ana Tenreiro: Data curation, Formal analysis, Writing - original draft, Writing - review \& editing. Isabel Sousa: Project administration, Supervision. Anabela Raymundo: Project administration, Supervision.

\section{Acknowledgments}

Portuguese Foundation for Science and Technology (FCT), UID/ AGR/04129/2013 - LEAF; Research Council of Norway, Algae to Future (A2F) Project; EUAlgae ES1408 COST Action; and Allmicroalgae company (Portugal) for the $C$. vulgaris samples.

\section{Authors' contributions}

MC Nunes was responsible for data acquisition, analysis and interpretation and for drafting the article and its critical revision. C Graça contributed to the acquisition of rheological data. A Tenreiro contributed to the acquisition and analysis of the flow cytometry data and revision of those sections of the manuscript. S Vlaisavljević contributed to the experiments assessing the antioxidant capacity and total phenolic compound contents, data analysis and revision of those sections of the manuscript. The study was designed and planned by I Sousa and A Raymundo, who approved the final version of the manuscript.

\section{Statement of informed consent, human/animal rights}

No conflicts, informed consent, human or animal rights were applicable to our work.

\section{Declaration of competing interest}

None of the authors has potential financial or other conflicts of interest to disclose.

\section{References}

[1] M. Plaza, M. Herrero, A. Cifuentes, H. Ibañez, Innovative natural functional ingredients from microalgae, J. Agric. Food Chem. 57 (16) (2009) 7159-7170, https://doi.org/10.1021/jf901070g.

[2] S.U. Kadam, P. Prabhasankar, Marine foods as functional ingredients in bakery and pasta products, Food Res. Int. 43 (2010) 1975-1980, https://doi.org/10.1016/j. foodres.2010.06.007.

[3] M.I. Khan, J.H. Shin, J.D. Kim, The promising future of microalgae: current status, challenges, and optimization of a sustainable and renewable industry for biofuels, feed, and other products, Microb. Cell Factories 17 (2018) 36, https://doi.org/10. 1186/s12934-018-0879-x.

[4] W.N. Phong, P.L. Show, T.C. Ling, J.C. Juan, E.-P. Ng, J.-S. Chang, Mild cell disruption methods for bio-functional proteins recovery from microalgae - recent developments and future perspectives, Algal Res. 31 (2018) 506-516, https://doi. org/10.1016/j.algal.2017.04.005.

[5] Bernaerts, T.M.M., Gheysen, L., Kyomugasho, C., Kermani, Z.J., Vandionant, S., Foubert, I., Hendrickx, M.E., Van Loey, A. M (2018). Comparison of microalgal biomass as functional ingredients: focus on the composition of cell wall related polysaccharides. Algal Res., 32: 150-161. doi:https://doi.org/10.1016/j.algal. 2018.03.017.

[6] E.M. Spiden, P.J. Scales, B.H.J. Yap, S.E. Kentish, D.R.A. Hill, G.J.O. Martin, The effects of acidic and thermal pretreatment on the mechanical rupture of two industrially relevant microalgae: Chlorella sp. and Navicula sp, Algal Res. 7 (2015) 5-10, https://doi.org/10.1016/j.algal.2014.11.006.

[7] Günerken, E., D'Hondt, E., Eppink, M.H.M., Garcia-Gonzalez, L., Elst, K., Wijiffels, R.H. (2015). Cell disruption for microalgae biorefineries. Biotechnol. Adv., 33: 243-260. doi:https://doi.org/10.1016/j.biotechadv.2015.01.008.

[8] D.-Y. Kim, D. Vijayan, R. Praveenkumar, J.-I. Han, K. Lee, J.-Y. Park, W.-S. Chang, J.-S. Lee, Y.-K. Oh, Cell-wall disruption and lipid/astaxanthin extraction from microalgae: Chlorella and Haematococcus, Bioresour. Technol. 199 (2016) 300-310, https://doi.org/10.1016/j.biortech.2015.08.107.

[9] E. D'Hondt, J. Martin-Juárez, S. Bolado, J. Kasperoviciene, J. Koreiviene, S. Sulcius, K. Elst, L. Bastiaens, Cell disruption technologies, Microalgae-Based Biofuels and Bioproducts, Woodhead Publishing, 2017.

[10] S.Y. Lee, J.M. Cho, Y.K. Chang, Y.-K. Oh, Cell disruption and lipid extraction for microalgal biorefineries: a review, Bioresour. Technol. 244 (2017) 1317-1328, https://doi.org/10.1016/j.biortech.2017.06.038.

[11] A.K. Lee, D.M. Lewis, P.J. Ashman, Disruption of microalgal cells for the extraction of lipids for biofuels: processes and specific energy requirements, Biomass Bioenergy 46 (2012) 89-101, https://doi.org/10.1016/j.biombioe.2012.06.034.

[12] Bernaerts, T.M.M., Panozzo, A., Doumen, V., Foubert, I., Gheysen, L., Goiris, K., Moldenaers, P., Hendrickx, M.E., Van Loey, A.M (2017). Microalgal biomass as a (multi)functional ingredient in food products: rheological properties of microalgal suspensions as affected by mechanical and thermal processing. Algal Res., 25: 452-463. doi:https://doi.org/10.1016/j.algal.2017.05.014.

[13] A.P. Batista, A. Raymundo, I. Sousa, J. Empis, Rheological characterization of coloured oil-in-water food emulsions with lutein and phycocyanin added to the oil and aqueous phases, Food Hydrocoll. 20 (1) (2006) 44-52, https://doi.org/10. 1016/j.foodhyd.2005.02.009.

[14] L. Gouveia, A.P. Batista, A. Raymundo, N. Bandarra, Spirulina maxima and Diacronema vlkianum microalgae in vegetable gelled desserts, Nutrition and Food Science 38 (5) (2008) 492-501, https://doi.org/10.1108/00346650810907010.

[15] A.P. Batista, M.C. Nunes, L. Gouveia, I. Sousa, A. Raymundo, F. Cordobés, A. Guerrero, J.M. Franco, Microalgae biomass interaction in biopolymer gelled systems, Food Hydrocoll. 25 (4) (2011) 817-825, https://doi.org/10.1016/j. foodhyd.2010.09.018.

[16] M. Fradique, A.P. Batista, M.C. Nunes, L. Gouveia, N.M. Bandarra, A. Raymundo, Incorporation of Chlorella vulgaris and Spirulina maxima biomass in pasta products. Part I: preparation and evaluation, J. Sci. Food Agric. 90 (10) (2010) 1656-1664, https://doi.org/10.1002/jsfa.3999.

[17] M. Fradique, A.P. Batista, M.C. Nunes, L. Gouveia, N. Bandarra, A. Raymundo, Isochrysis galbana and Diacronema vlkianum biomass incorporation in pasta products as PUFA's source, LWT-Food Science and Technology 50 (2013) 312-319, https:// doi.org/10.1016/j.lwt.2012.05.006.

[18] L. Gouveia, C. Coutinho, E. Mendonça, A.P. Batista, I. Sousa, N.M. Bandarra, A. Raymundo, Functional biscuits with PUFA- $\omega 3$ from Isochrysis galbana, J. Sci. Food Agric. 88 (5) (2008) 891-896, https://doi.org/10.1002/jsfa.3166.

[19] A.P. Batista, A. Nicccolai, P. Fradinho, S. Fragoso, I. Bursic, L. Rodolfi, N. Biondi, M.R. Tredici, I. Sousa, A. Raymundo, Microalgae biomass as an alternative ingredient in cookies: sensory, physical and chemical properties, antioxidant activity and in vitro digestibility, Algal Res. 26 (2017) 161-171, https://doi.org/10.1016/j. algal.2017.07.017.

[20] C. Graça, P. Fradinho, I. Sousa, A. Raymundo, Impact of Chlorella vulgaris on the rheology of wheat flour dough and bread texture, LWT-Food Science and Technology 89 (2018) 466-474, https://doi.org/10.1016/j.lwt.2017.11.024.

[21] A.P. Batista, L. Gouveia, N.M. Bandarra, J.M. Franco, A. Raymundo, Comparison of microalgal biomass profiles as novel functional ingredient for food products, Algal Res. 2 (2013) 164-173, https://doi.org/10.1016/j.algal.2013.01.004. 
[22] P.L. Bergquist, E.M. Hardiman, B.C. Ferrari, T. Winsley, Applications of flow cytometry in environmental microbiology and biotechnology, Extremophiles 13 (3) (2009) 389-401, https://doi.org/10.1007/s00792-009-0236-4.

[23] M. Díaz, M. Herrero, L.A. García, C. Quirós, Application of flow cytometry to industrial microbial bioprocesses, Biochem. Eng. J. 48 (3) (2010) 385-407, https:// doi.org/10.1016/j.bej.2009.07.013.

[24] I. Buresová, S. Krácmar, P. Dvoráková, T. Streda, The relationship between rheological characteristics of gluten-free dough and the quality of biologically leavened bread, J. Cereal Sci. 60 (2014) 271-275, https://doi.org/10.1016/j.jcs.2014.07. 001.

[25] C. Sánchez-Moreno, J.A. Larrauri, F. Saura-Calixto, A procedure to measure the antiradical efficiency of polyphenols, J. Sci. Food Agric. 76 (2) (1998) 270-276, https://doi.org/10.1002/(SICI)1097-0010(199802)76:2<270::AID-JSFA945 > 3.0 CO;2-9.

[26] I.F.F. Benzie, J.J. Strain, The ferric reducing ability of plasma (FRAP) as a measure of "antioxidant power": the FRAP assay, Anal. Biochem. 239 (1) (1996) 70-76, https://doi.org/10.1006/abio.1996.0292.

[27] L.R. Fukumoto, G. Mazza, Assessing antioxidant and prooxidant activity of phenolic compounds, J. Agric. Food Chem. 48 (8) (2000) 3597-3604, https://doi.org/10. 1021/jf000220w.

[28] C. Safi, C. Frances, A.V. Ursu, C. Laroche, C. Pouzet, C. Vaca-Garcia, P.-Y. Pontalier, Understanding the effect of cell disruption methods on the diffusion of Chlorella vulgaris proteins and pigments in the aqueous phase, Algal Res. 8 (2015) 61-68, https://doi.org/10.1016/j.algal.2015.01.002.

[29] Günerken, E., D'Hondt, E., Eppink, M.H.M., Elst, K., Wijiffels, R.H. (2017). Flow cytometry to estimate the cell disruption yield and biomass release of Chlorella sp. during bead milling. Algal Res., 25: 25-31. doi:https://doi.org/10.1016/j.algal 2017.04.033.

[30] N. Samarasinghe, S. Fernando, R. Lacey, W.B. Faulkner, Algal cell rupture using high pressure homogenization as prelude to oil extraction, Renew. Energy 48 (2012) 300-308, https://doi.org/10.1016/j.renene.2012.04.039.

[31] C. Safi, A.V. Ursu, C. Laroche, B. Zebib, O. Merah, P.-Y. Pontalier, C. Vaca-Garcia, Aqueous extraction of proteins from microlagae: effect of different cell disruption methods, Algal Res. 3 (2014) 61-65, https://doi.org/10.1016/j.algal.2013.12.004.

[32] L. Grossmann, S. Ebert, J. Hinrichs, J. Weiss, Production of protein-rich extracts from disrupted microalgae cells: impact of solvent treatment and lyophilization, Algal Res. 36 (2018) 67-76, https://doi.org/10.1016/j.algal.2018.09.011.

[33] N. Unterlander, P. Champanhe, W. Plaxton, Lyophilization pretreatment facilitates extraction of soluble proteins and active enzymes from the oil-accumulating microalga Chlorella vulgaris, Algal Res. 25 (2017) 439-444, https://doi.org/10.1016/j. algal.2017.06.010.

[34] Y.M. Heo, H. Lee, C. Lee, J. Kang, J.-W. Ahn, Y.M. Lee, K.-Y. Kang, Y.-E. Choi, J.J. Kim, An integrative process for obtaining lipids and glucose from Chlorella vulgaris biomass with a single treatment of cell disruption, Algal Res. 27 (2017) 286-294, https://doi.org/10.1016/j.algal.2017.09.022.

[35] S. Tietze, M. Jekle, T. Becker, Possibilities to derive empirical dough characteristics from fundamental rheology, Trends Food Sci. Technol. 57 (2016) 1-10, https://doi. org/10.1016/j.tifs.2016.08.016.

[36] A. Rieder, A.K. Holtekjolen, S. Sahlstrom, A. Moldestad, Effect of barley and oat flour types and sourdoughs on dough rheology and bread quality of composite wheat bread, J. Cereal Sci. 55 (2012) 44-52, https://doi.org/10.1016/j.jcs.2011 10.003.

[37] A.M. Janssen, T. van Vliet, J.M. Vereijken, Rheological behaviour of wheat glutens at small and large deformations. Comparison of two glutens differing in bread making potential, J. Cereal Sci. 23 (1996) 19-31, https://doi.org/10.1006/jcrs. 1996.0002

[38] P. García-Segovia, M.J. Pagán-Moreno, I.F. Lara, J. Martínez-Monzó, Effect of microalgae incorporation on physicochemical and textural properties in wheat bread formulation, Food Sci. Technol. Int. 0 (0) (2017) 1-11, https://doi.org/10.1177/ 1082013217700259.

[39] F.S. Figueira, T.M. Crizel, C.R. Silva, M.M. Salas-Mellado, Elaboration of gluten-free bread enriched with the microalgae Spirulina platensis, Brazilian Journal of Food Technology 14 (4) (2011) 308-316, https://doi.org/10.4260/ BJFT2011140400037.

[40] R. Rózylo, W.H. Hassoon, U. Gawlik-Dziki, M. Siastala, D. Dziki, Study on the physical and antioxidant properties of gluten-free bread with brown algae, CyTA-Journal of Food 15 (2) (2017) 196-203, https://doi.org/10.1080/19476337. 2016.1236839.

[41] F.J. Francis, F.M. Clydesdale, Food Colorimetry: Theory and Applications, The AVI Publishing Company Inc, Westport, 1975.

[42] M.R. Catellar, J.M. Obón, J.A. Fernández-Lopez, The isolation and properties of a concentrated red-purple betacyanin food colourant from Opuntia stricta fruits, J. Sci. Food Agric. 86 (1) (2006) 122-128, https://doi.org/10.1002/jsfa.2285.

[43] T. Goodwin, G. Britton, Distribution and analysis of carotenoids, in: T.W. Goodwin (Ed.), Plant Pigments, Academic Press, 1988, pp. 61-132.

[44] U.M. Lanfer-Marquez, R.M. Barros, P. Sinnecker, Antioxidant activity of chlorophylls and their derivatives, Food Res. Int. 38 (8) (2005) 885-891, https://doi. org/10.1016/j.foodres.2005.02.012.

[45] N. Zouari, M. Abid, N. Fakhfakh, M.A. Ayadi, L. Zorgui, M. Ayadi, H. Attia, Bluegreen algae (Arthrospira platensis) as an ingredient in pasta: free radical scavenging activity, sensory and cooking characteristics evaluation, Int. J. Food Sci. Nutr. 62 (8) (2011) 811-813, https://doi.org/10.3109/09637486.2011.582461.

[46] E. Rodríguez De Marco, M.E. Steffolani, C.S. Martínez, A.E. León, Effects of spirulina biomass on the technological and nutritional quality of bread wheat pasta, LWT-Food Science and Technology 58 (2014) 102-108, https://doi.org/10.1016/j. lwt.2014.02.054.

[47] Y. Shen, G. Cheng, Y. Li, Bread characteristics and antioxidant activities of Maillard reaction products of white pan bread containing various sugars, LWT-Food Science and Technology 95 (2018) 308-315, https://doi.org/10.1016/j.lwt.2018.05.008.

[48] L. Machu, L. Misurcova, J.V. Ambrozova, J. Orsavova, J. Mlcek, J. Sochor, T. Jurikova, Phenolic content and antioxidant capacity in algal food products, Molecules 20 (2015) 1118-1133, https://doi.org/10.3390/molecules20011118. 